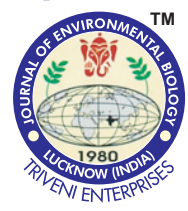

\title{
Biosorption of synthetic dyes from textile industrial effluent using waste papaya latex
}

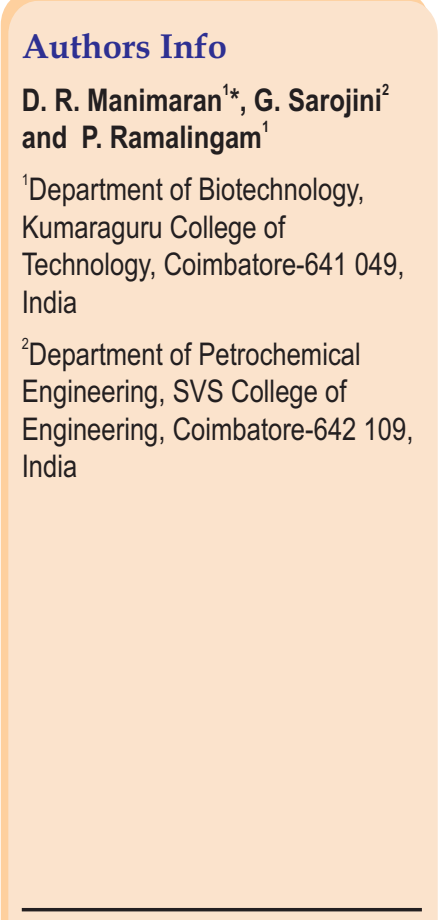

*Corresponding Author Email : manimaran.dr.bt@kct.ac.in

\section{Edited by \\ Professor M. Seenuvasan}

Reviewed by

Dr. T. Anitha

Dr. G.L. Sathyamoorthy

\section{Abstract}

Aim: The effect of $\mathrm{pH}$, adsorbent concentration, time, initial dye concentration and agitation speed on adsorption capacity of papaya latex as an adsorbent was investigated.

Methodology: The biosorption experiments were carried out in batch process by means of conical flask and agitated in a thermostated shaking incubator at rpm for a suitable contact time at different temperature range. The experiments were carried out at different $\mathrm{pH}(4-9)$, fixed biosorbent dosage, temperature, contact time, initial dye concentration and agitation speed. The samples were withdrawn at regular intervals and the concentration of dyes were analyzed using a UV-Visible spectrometer.

Results: The adsorption studies revealed that papaya latex removed about $83.18 \%$ of the reactive red dye and $87.97 \%$ of deep marine blue dye from aqueous phase under optimal conditions. The maximum adsorption of both dyes was found at $\mathrm{pH}$ 4. Adsorption isotherms such as Langmuir, Freundlich, Temkin and Dubin models were attempted to predict equilibrium data. The pseudo-first-order kinetics provide the best correlation of experimental data.

Interpretation: Waste papaya latex can be used as an eco-friendly and low-cost adsorbent in removal of reactive red dye and deep marine blue from textile effluent.

Key words: Deep marine blue dye, Kinetics, Isotherm, Papaya latex, Reactive red dye
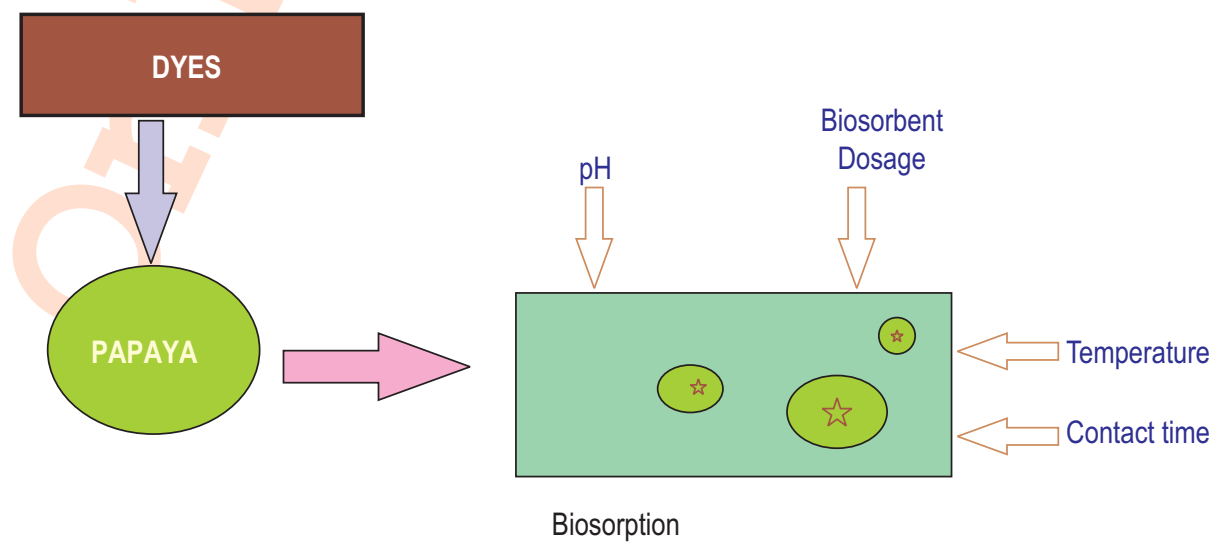

How to cite : Manimaran, D. R., G. Sarojini and P. Ramalingam: Biosorption of synthetic dyes from textile industrial effluent using waste papaya latex. J. Environ. Biol., 40, 817-824 (2019). DOI : http://doi.org/10.22438/jeb/40/4(SI)/JEB_28 


\section{Introduction}

Textile industry is one of the most important chemically intensive industries that has significance throughout the world. On earth, it is one of the leading water consumer industries and the highest polluter of clean water. About 2,000 different chemicals are used in processing of dye in textile industries, from dyes to transfer agents (Deniz and Kepekci, 2016). The pollution load on the liquid effluent increases with subsequent steps of chemical processing, where contribution of one single dyeing step amounts to about $8-20 \%$ of the total pollution load due to incomplete exhaustion of dye (Dallel et al., 2018). Water consumption in chemical processing operation varies from 50 $300 \mathrm{I}$ per $\mathrm{kg}$ of the processing goods, so that a mill processing $100,000 \mathrm{mt}$ of cotton per day may require water varying from 2.5 to 4.0 million litre per day. About 40,000 to 80,000 tons of dyes are estimated to be discharged every year in textile processing units on global basis. Dye production in India is estimated to be around $64,000 \mathrm{MT}$, which is about $6.6 \%$ of the world production. There are around 700 varieties of dyes and dye intermediates produced in India (Hameed, 2009)

A huge amount of synthetic dyes are produced to meet the society needs, exports and as a basic material for various industries every day. About $50 \%$ of the dyes are lost to textile processing unit effluent during dyeing and finishing operations due to lack of proper methodology and inefficiency of dyeing process (Cengiz et al., 2012). Most dyes escape from convention treatment process as they are highly stable and it is difficult to remove them. Various methods like adsorption (Annadurai et al., 2002., Chiou and Li, 2002), oxidative and reductive treatments (Aplin and White, 2000; Tokuda et al., 1999; Yoshida et al., 2001; Alvarex and Pletcher, 1999), electrochemical treatment with flocculation (Marzinokowaki and Van Clewe, 1998) and membrane separation (Diaper et al., 1996) have been widely used for removal of dyes in textile and dyes effluents. Each technology has its own merits and demerits. The treated effluents contain high BOD and synthetic complex aromatic agents which adversely affect the aquatic environment (Bhunia, et al., 2001; Lin and Peng, 1994).

Currently, biosorption method is considered to be effective in removal of dyes from effluents as it is a simple, ecofriendly and easy handling. In this process, a soluble dye from effluent is transferred to the adsorbent solid surface (Zaharia and Susteu, 2012). However, choosing a suitable adsorbent is a major task. Adsorbent is produced from variety of materials such as cucumber peel, wheat shells (Bulut and Aydin, 2006; Ahalya et al., 2012), rice husk ash (Chowdhar et al., 2011) and agricultural wastes (Adegoke and Bello 2015; Nirmal Kumar and Cini Oommen, 2012).

The latex of Carica papaya is a rich source of cystein, endopeptidases, including papain, glycyl endopeptidase, chymopapain and caricain, which constitute more than $80 \%$ of the whole enzyme fraction. Papain (EC 3.4.22.2) is a minor constituent $(5-8 \%)$ among the papaya endopeptidases. The enzyme is widely used as meat tenderizer, and have several other applications, e.g., defibrinating wounds, treatment of edemas, shrink proofing of wool, etc. (Thippeswamy et al., 2012)

The current work focus on removal of dye using waste papaya latex biomass and to study the effect of operating parameters such as $\mathrm{pH}$, biosorbent dosage, initial dye concentration, contact time, agitation and temperature.

\section{Materials and Methods}

Commercial deep marine blue dye and reactive red dye were obtained from local industries. The chemicals such as sodium hydroxide, hydrochloric acid were obtained from Fissure chemicals. The materials such conical flasks, pipettes, test tubes, beakers etc, were obtained from Borosil Ltd. UV- Visible spectrometers as well as $\mathrm{pH}$ meters of the brands Shimadzu and Elico were used for the analysis part of the experiments.

Collection and preparation of sample: Reactive red and deep marine blue dyes were provided by Clariant Chemicals, Tiruppur, Tamil Nadu, India. The dye was stored at $4{ }^{\circ} \mathrm{C}$ for experimental studies. Papaya latex was collected from Senthil Papain and Food Products Pvt. Ltd.

Biosorption experimental procedure: Biosorption experiments were carried out by batch process and agitated in a thermostated shaking incubator for a suitable contact time of $45 \mathrm{~min}$ at different temperature (298-333 K). The experiments were carried out at initial $\mathrm{pH}$ of dye solution ( 1 to 8 ), fixed biosorbent dosage ( 0.05 to $3 \mathrm{~g}$ ) using $50 \mathrm{ml}$ of initial concentration of dye solution. At regular intervals, the samples were withdrawn and the residual concentration of Deep Marine Blue and Reactive Red were analyzed using a UV-Visible spectrometer.

The amount of dye biosorbed onto gram of absorbent was calculated by the equation given below

$$
q_{e}=\frac{\left(C_{0}-C_{e}\right)}{m} \times V
$$

where, $\mathrm{q}_{\mathrm{e}}$ is the amount of dye biosorbed at equilibrium $\left(\mathrm{mg} \mathrm{g}^{-1}\right)$; $\mathrm{V}$ is the volume of dye solution (I) and $\mathrm{m}$ is the mass of biosorbent used $(\mathrm{g})$.

\section{Results and Discussion}

The effect of $\mathrm{pH}$ was observed on adsorption of Red Dye and Deep Marine Blue Dye at $30^{\circ} \mathrm{C}$ and $25 \mathrm{mg} \mathrm{l}^{-1}$ dye concentration (Fig. 1). The maximum bioadsorption was found at $\mathrm{pH} 4$ and removal of dye decreased with increase in $\mathrm{pH}$ (Belala et al., 2011). The results confirm that the dye possess negative 
charge due to the presence of sulphonate groups. The percentage of dye was higher in acidic solution and lower in basic solution. The increase in $\mathrm{pH}$ increased the number of negative charged active sites on the adsorbent which decreases the possibility of sorption of dyes on negatively charged surface as dyes are anionic (McMullan, 2001). Interestingly, similar kind of results were not observed for metal ions (Adie Gilbert et al., 2011).

The removal ability of waste Papaya latex was determined by biosorbent dosage. The effect of biosorbent was examined by varying the biosorbent dosage from 0.02 to $0.3 \mathrm{~g}$ at initial dye concentration of $25 \mathrm{mg} \mathrm{l}^{-1}$ and initial $\mathrm{pH} 4.0$ (Fig. 2). The results revealed that the increase in dosage decreased the biosorption capacity for both dyes due to increase in surface available for dye biosorption (Farkas et al., 2013).

The effect of initial dye concentration was investigated by varying the initial dye concentration in the range of $10-50 \mathrm{mg} \mathrm{I}^{-1}$ at biosorbent dosage of $0.1 \mathrm{~g}$ for DMB, $0.05 \mathrm{~g}$ for RR and 4.0 initial $\mathrm{pH}$ (Fig. 3). Previous studies have reported that biosorption capacity increases with initial dye concentration due to larger driving force offered by initial concentration of dye to overcome the mass transfer resistance (Georgieva et al., 2015).

To investigate the effect of contact time on adsorption process, the contact time varied from 25 to $120 \mathrm{~min}$ at minimum dosage of $1 \mathrm{~g} 100 \mathrm{ml}^{-1}, \mathrm{pH} \mathrm{4}$, temperature of $30^{\circ} \mathrm{C}$ and initial concentration of $25 \mathrm{mg} \mathrm{l}^{-1}$ (Fig. 4). It was observed that dye removal efficiency increased with contact time up to $60 \mathrm{~min}$ for reactive red dye (Belala et al., 2011) and remains constant on further increase of contact time due to the availability of vacant sites during the initial stage and non-availability of vacant sites after the attainment of equilibrium (Kamranifar et al., 2018). In case of deep marine blue removal efficiency increased up to 45 min and remained constant on further increase in time.

In order to determine the effect of temperature on biosorption capacity, the experiments were carried out at temperatures ranging from 303 to $323 \mathrm{~K}$ with the initial dye concentration of $25 \mathrm{mgl}^{-1}$ (Fig. 5). It was observed that biosorption increased with increase in temperature as the rise of temperature enhances the mass transfer diffusion rate and raises the number of active sites (Iqbal and Saeed, 2007).

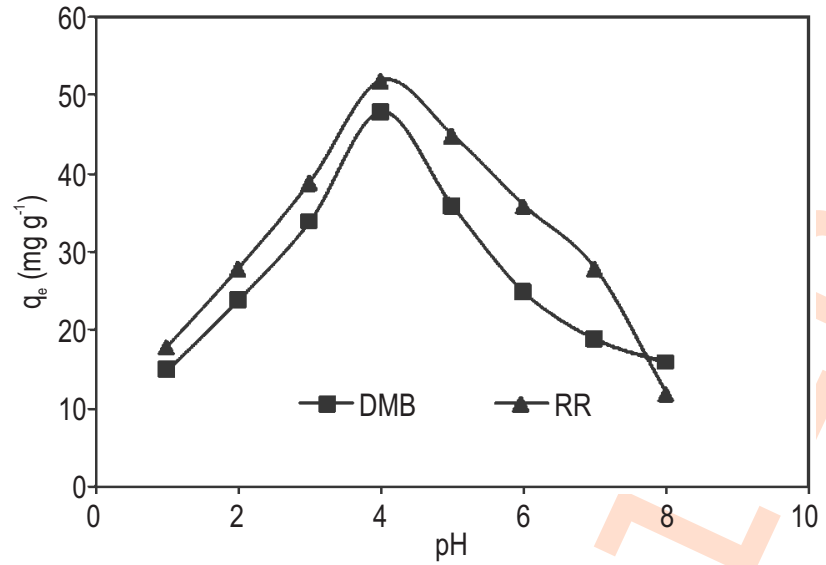

Fig. 1 : Effect of $\mathrm{pH}$.

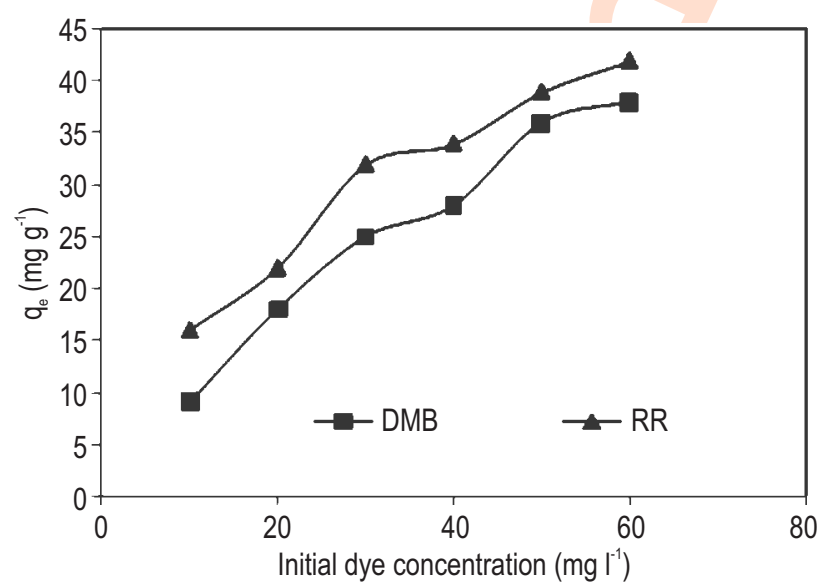

Fig. 3 : Effect of initial dye concentration.

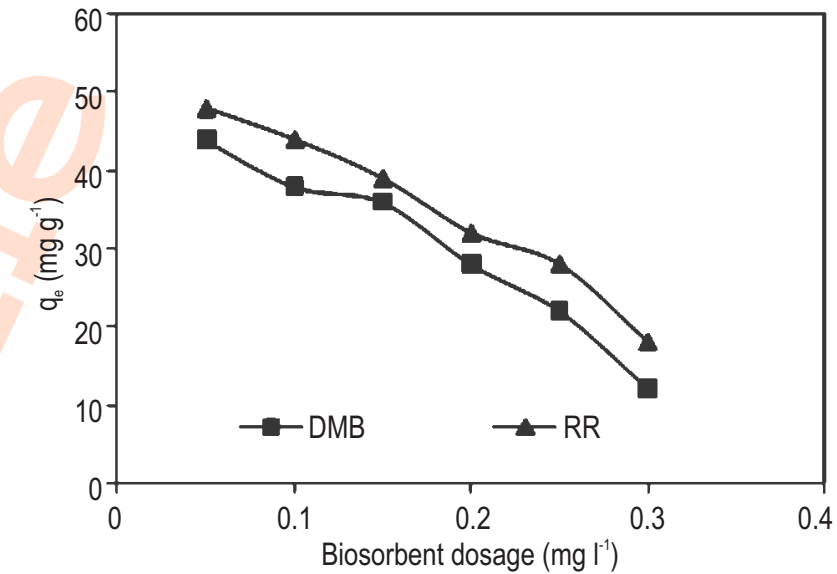

Fig. 2 : Effect of biosorbent dosage.

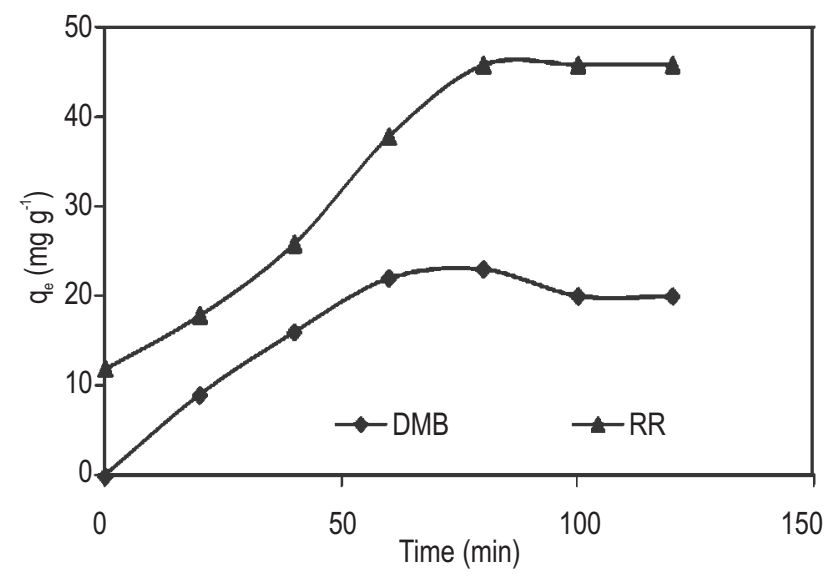

Fig. 4 : Effect of contact time. 


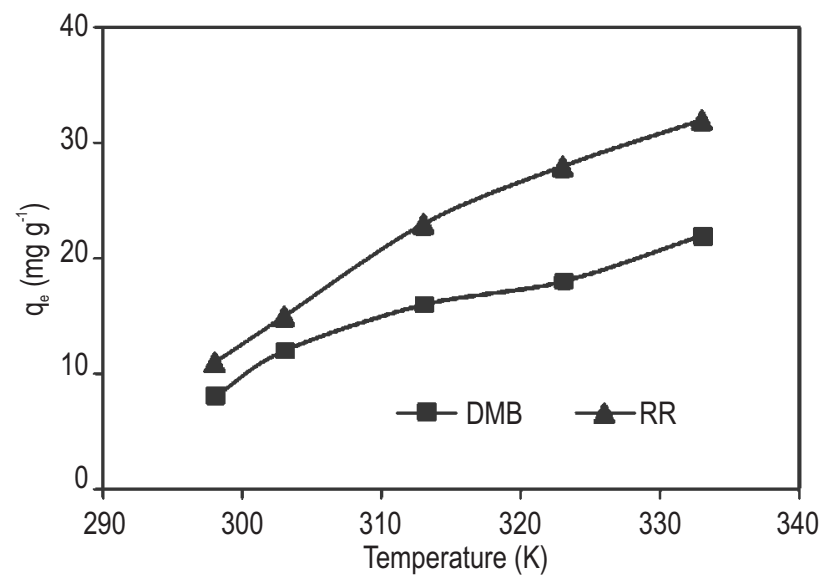

Fig. 5 : Effect of temperature.

To investigate the effect of agitation on biosorption capacity, the agitation time varied from 50 to $175 \mathrm{rpm}$. The biosorption capacity increased with agitation up to $125 \mathrm{rpm}$ for both cases of dye and decreased on further increase on agitation (Fig. 6). The results revealed that the agitation has a significant effect on removal of dye due to the effect of higher diffusion rate of the adsorbate into the intraparticle pores of the adsorbent (Khan et al., 2018).

Different isotherms such as Langmuir isotherm (Fig. 7a), Freundlich isotherm (Fig. 7b), Temkin isotherm (Fig. 7c) and Dubin- Radushkevich (D-R) isotherm (Fig. 7d) are used to represent the kinetic behavior of dye adsorption. The isotherms Langmuir, Freundlich were identified as best adsorption isotherms for dye removal for both reactive red and deep marine blue dyes. Adsorption process is described by isotherms which connect the amount of adsorbate on the adsorbent (Singh et al., 2018). Distribution of metal ions between the adsorbate and adsorbent and the equilibrium data were analyzed by several isotherms such as Langmuir, Freundlich and Tempkin models. Langmuir adsorption model is derived for single adsorbate case and adsorbate sites with homogeneous surface (Dada et al., 2012). Langmuir adsorption model is given by the equation below:

$$
\frac{1}{q_{c}}=\frac{1}{q_{0}}+\frac{1}{q_{0} K_{L} C_{e}}
$$

Where, $q_{e}$ is the amount of metal adsorbed per gram of the adsorbate at equilibrium $\left(\mathrm{mg} \mathrm{g}^{-1}\right), q_{0}$ is the maximum monolayer coverage capacity $\left(\mathrm{mg} \mathrm{g}^{-1}\right), K_{L}$ is the Langmuir isotherm constants $\left(\mathrm{L} \mathrm{mg}^{-1}\right)$, and $C_{e}$ is the equilibrium concentration of the adsorbate (mg l-1). The values of $q_{0}$ and $K{ }_{L}$ were computed from the slopes and intercepts of Langmuir plot of $1 / q_{e}$ vs. $1 / C_{e}$. The value of $R_{L}$ decides the type of isotherm and it was determined to be less than 1, which indicates that Langmuir isotherm is suited for the adsorption (Morosanu et al., 2018).

$$
R_{L}=\frac{1}{1+\left(1+K_{L} C_{V}\right)}
$$

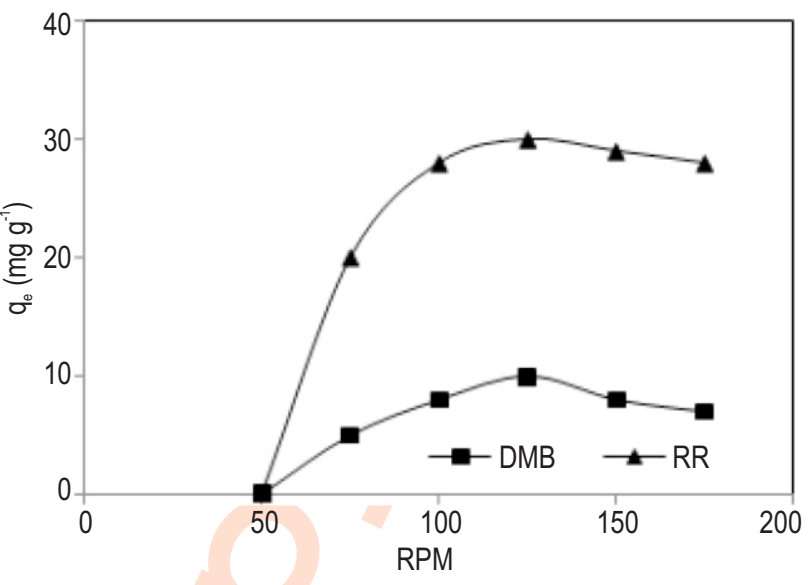

Fig. 6 : Effect of agitation speed (rpm).

Frendlich isotherm is significant multisite adsorption isotherm for uneven surfaces and is given by:

$$
\log q_{e}=\log K_{f}+\frac{1}{n} \log C_{e}
$$

where, $K_{f}$ is the Freundlich isotherm $\left(\mathrm{mg} \mathrm{g}^{-1}\right), n$ is the adsorption intensity, $C_{e}$ is the equilibrium concentration of adsorbate $\left(\mathrm{mg} \mathrm{l}^{-1}\right)$, and $q_{e}$ is the amount of metal adsorbed per gram of adsorbate at equilibrium ( $\mathrm{mg} \mathrm{g}^{-1}$ ) (Nayak and Pal, 2017). The constant $K_{f}$ is an indicator of adsorption capacity, while $1 / n$ is a function of strength of adsorption in adsorption process which was found by linear plot. From the data obtained, the value of $1 / n$ was 0.706 and the value of $n$ was found to be greater than unity ( $n$ $=1.416$ ), confirming higher affinity between the sorbent and sorbate (Khalaf, 2008).

Temkin isotherm is derived for heterogeneous surface energy system:

$$
q_{e}=\frac{R T}{b} \ln A_{T} C_{e}
$$

Where, $\quad A_{T}=$ Temkin isotherm equilibrium binding constant $\left(\mathrm{L} \mathrm{g}^{-1}\right) ; \mathrm{T}=$ Temkin isotherm constant; $\mathrm{R}=$ universal gas constant $\left(8.314 \mathrm{~J} \mathrm{~mol}^{-1} \mathrm{~K}^{-1}\right) ; \mathrm{T}=$ Temperature at $298 \mathrm{~K} ; \mathrm{b}=$ Constant related to heat of sorption $\left(\mathrm{J} \mathrm{mol}^{-1}\right)$ (Singh et al., 2017). The heat of sorption (b) and At values were calculated to be $7.038 \mathrm{~J} \mathrm{~mol}^{-1}$ and $0.1686 \mathrm{I} \mathrm{mg}^{-1}$ from the slope and the intercept of linearized Temkin plot which indicates that it was a physical adsorption (Ncibi et al., 2009).

Dubinin-Radushkevich isotherm is given by:

$$
q_{e}=q_{s} \exp \left(-k_{a d} \varepsilon^{2}\right)
$$

Where, $q_{e}, q_{s}, K_{a d}$, are constants; $q_{e}$ is the amount of adsorbate in the adsorbent at equilibrium $\left(\mathrm{mg} \mathrm{g}^{-1}\right) ; q_{\mathrm{s}}$ is the theoretical isotherm saturation capacity $\left(\mathrm{mg} \mathrm{g}^{-1}\right) ; \mathrm{K}_{\mathrm{ad}}$ is the Dubinin-Radushkevich isotherm constant $\left(\mathrm{mol}^{2} \mathrm{~kJ}^{-2}\right.$ ) and Dubinin-Radushkevich isotherm constant (Shakoor and Nasar, 2017). 
The adsorption phenomenon is determined by the kinetics of adsorption process. Kinetic mechanism of the adsorption is evaluated by means of pseudo- first order models. The validity of order of reaction was determined by regression coefficients, the predicted $Q_{e}$ values and Chi- square (Rangabhashiyam et al., 2018). The correlation coefficients express the predicted values for the model. A model with higher correlation coefficient suits the adsorption kinetics successfully. Biosorption is found to follow pseudo first order kinetics (Unuabonah et al., 2009).

The rate expression for pseudo first order kinetics is given by

$$
\log C_{e}=\frac{k_{1}}{2.303} t+\log C_{0}
$$

Where, $\mathrm{C}_{0}$ and $\mathrm{C}_{\mathrm{e}}$ are the concentration $\left(\mathrm{mg} \mathrm{l}^{-1}\right)$ of chromium ions at initial and at time, respectively, and $k_{1}$ is the first order rate constant $\left(\mathrm{min}^{-1}\right)$ and $\mathrm{t}$ is the time of adsorption process. The graph of $\log C_{e}$ vs. $t$ gives the value of rate constant and regression coefficients. The slope of the plot predicts the rate constant and the intercept of the plot gives the regression coefficient (Wanyonyi et al., 2014).

Langmuir isotherm model

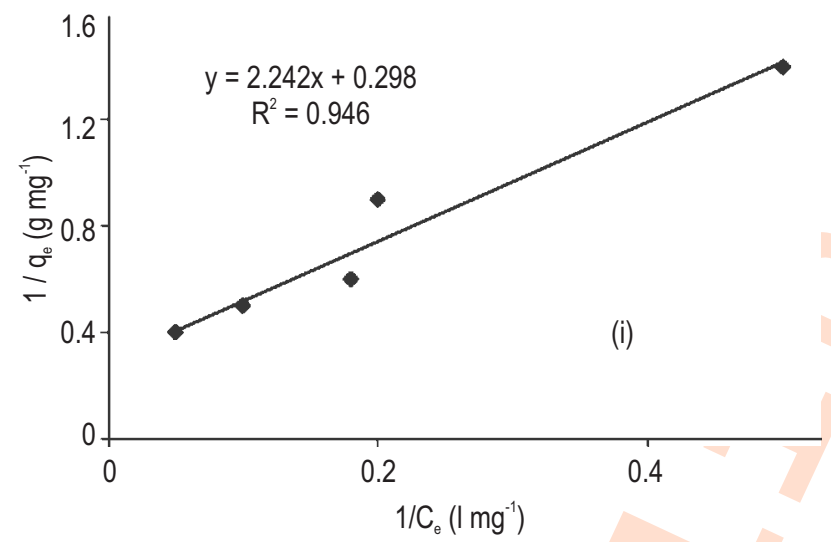

Fig. 7(a) : Langmuir plots for dyes removal (I) and RR (ii) DMB.

Freundlich isotherm model

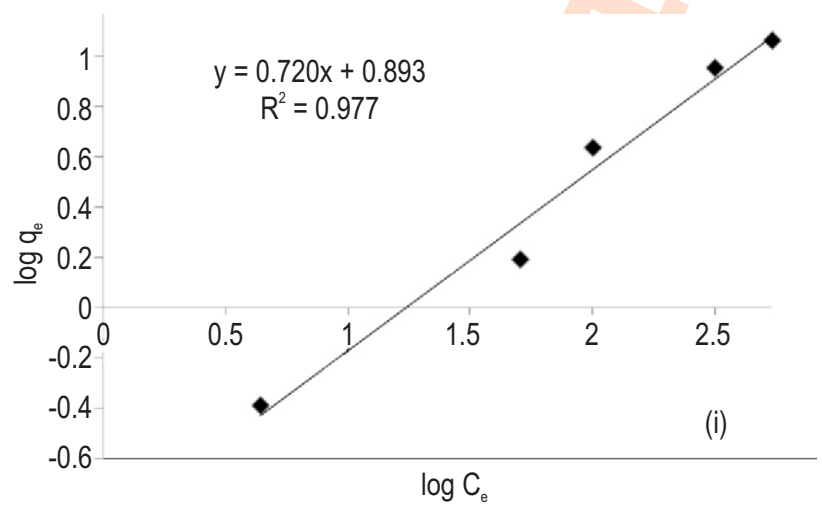

The integrated form of pseudo-first-order-kinetics is expressed by:

$$
\log \left(q_{O}-q_{e}\right)=\log \left(q_{O}\right)-\frac{k_{1}}{2.303} t
$$

Where, $q_{o}$ and $q_{e}$ are the amount $\left(\mathrm{mg} \mathrm{g}^{-1}\right)$ of ions at initial and at time $t$, respectively, and $k_{1}$ is the first order rate constant $\left(\mathrm{min}^{-1}\right)$ and $t$ is the time of adsorption process. The linear plot of $\log \left(q_{0}-q_{e}\right)$ vs. $t$ predicts the applicability of process (Saeed et al., 2009).

FTIR analysis of the adsorbent papaya latex showed two peaks at wave numbers $\mathrm{OH}$ stretching and $-\mathrm{C}=\mathrm{C}$ stretching, respectively (Fig. 8). The spectrum showed peaks at $3354.715 \mathrm{~cm}^{-1}$ which confirms the presence of free hydroxyl groups of carboxylic acids, alcohols and phenol on the surface of the adsorbent and the peak at $1633.03 \mathrm{~cm}^{-1}$ represents the bending vibrations of $\mathrm{O}-\mathrm{C}-\mathrm{H}, \mathrm{C}-\mathrm{C}-\mathrm{H}$ and $\mathrm{C}-\mathrm{O}-\mathrm{H}$ groups (Pavan et al., 2014).

The study revealed that papaya latex could be effectively used to remove Reactive red dye and deep marine blue dye from
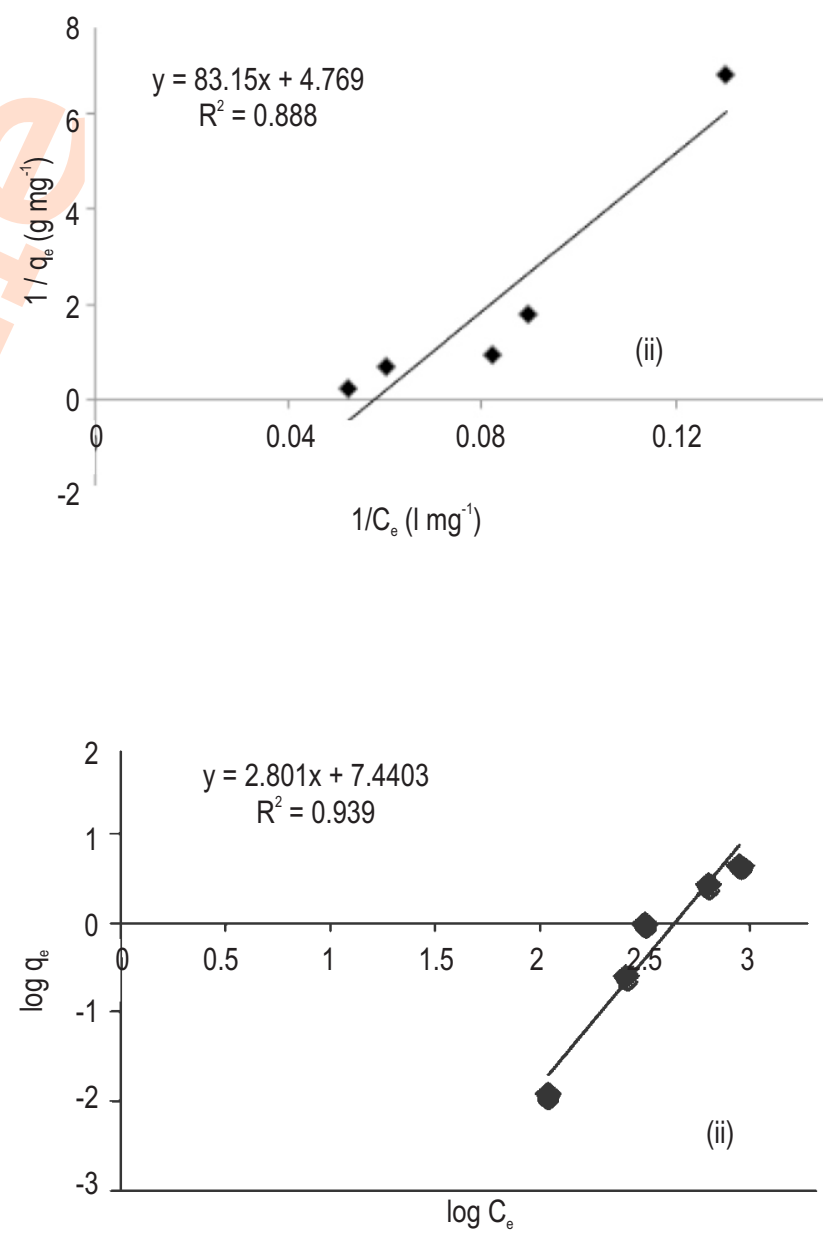

Fig. 7(b) : Freundlich plots for dyes removal (I) RR and (ii) DMB. 
Temkin isotherm model
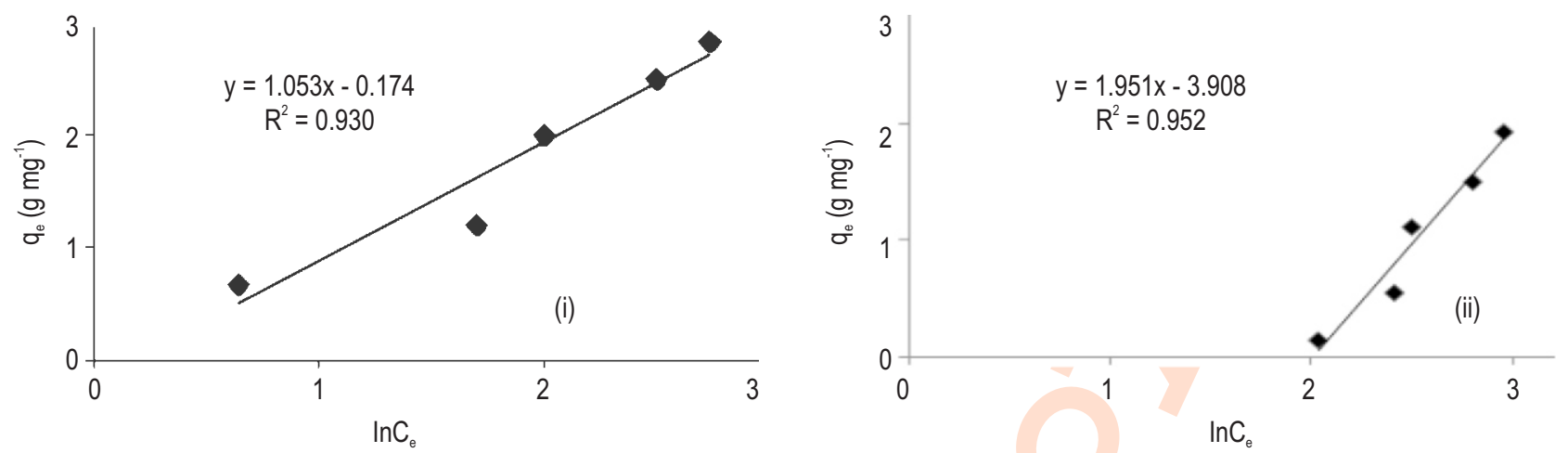

Fig. 7(c) : Temkin plots for dye removal (i) RR and (ii) DMB.

Dubin - Radushkevich (D-R) isotherm model
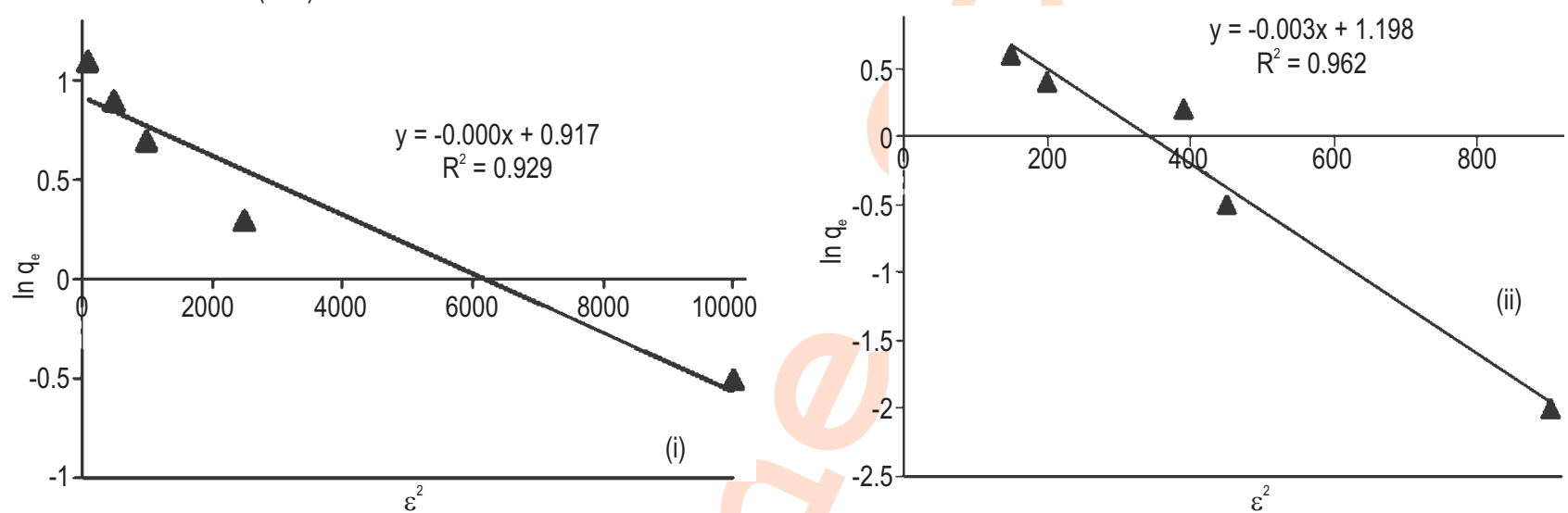

Fig. 7(d) : Dubin -Radushkevich (D-R) plots for dye removal (i) RR and (ii) DMB.

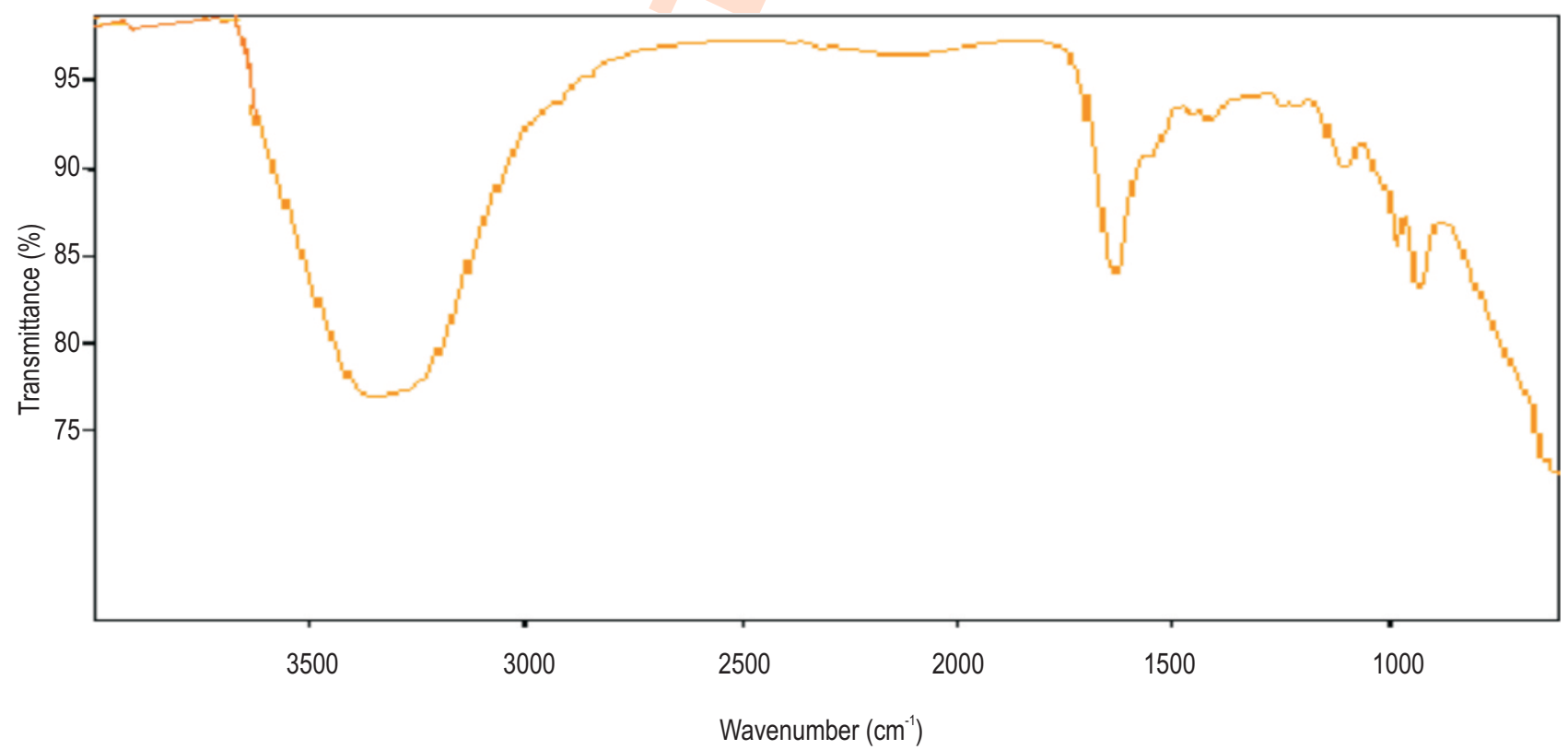

Fig. 8 : FTIR analysis for adsorbent (papaya latex). 
an aqueous solution. At pH 4, adsorbent concentration of $1.6 \mathrm{~g}$ $100 \mathrm{ml}^{-1}$ and incubation of $45 \mathrm{~min}$ maximum removal was observed for deep marine blue dye. At pH 4, adsorbent

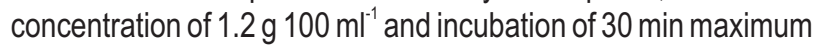
removal was observed for reactive red dye. It was found that the adsorption process by papaya latex as an adsorbent could be well described by both Freundlich and Langmuir isotherm. Furthermore, a pseudo-first-order kinetics showed to be well suited with the rate of adsorption. Although, the generation of effluents containing direct dyes by textile industry is almost unavoidable, the results of the experimental studies can help to design an appropriate remediation plan to minimize the unfavorable impacts caused by industrial effluents. Further studies on natural absorbents like latex of papaya their characteristics and efficiency on large scale would reveal whole new prospect for remediation of industrial pollutants.

\section{References}

Adegoke, K.A and O.S. Bello: Dye sequestration using agricultural wastes as adsorbents. Wat. Res. Ind., 12, 8-24 (2015).

Adie Gilbert, U., I.U. Emmanuel, A.A. Adebanjo and G.A. Olalere: Biosorptive removal of $\mathrm{Pb}^{2+}$ and $\mathrm{Cd}^{2+}$ onto novel biosorbent: Defatted Carica papaya seeds. Biomass Bioenergy, 35, 25172525 (2011).

Ahalya, N., R.D. Kanamadi and T.V. Ramachandra: $\mathrm{Cr}$ (VI) and Fe (III) removal using Cajanus Cajan husk. J. Environ. Biol., 33, 27-31 (2012)

Alvarez-Gallegos, A. and D. Pletcher: The removal of low level organics via hydrogen peroxide formed in reticulated vitreous carbon cathode cell. Electrochim. Acta., 44, 2483-2492 (1999).

Annadurai, G., R.S. Juang and D.J. Lee: Use of cellulose based wastes for adsorption of dyes from aqueous solutions. J. Haz. Mate., 92, 263-274 (2002).

Aplin, R. and T.D. White: Comparison of three advanced oxidation processes for degradation of textile dyes. Wat. Sci. Technol., 42, 345-354 (2000).

Bhunia, A., S. Durani and P. Wangikar: Horseradish peroxidase catalyzed degradation of industrially important dyes. Biotechnol. Bioengg.,72, 562-567 (2001).

Bulut, Y. and H.Aydin: A kinetics and thermodynamics study of methylene blue adsorption on wheat shells. Desalination, 194, 259-267 (2006).

Cengiz, S., F. Tanrikulu and S. Aksu S: An alternative source of adsorbent for the removal of dyes from textile waters: Posidonia oceanica (L.). Chem. Eng. J.,189-190, 32-40 (2012)

Chiou, M.S. and H.Y. Li: Equilibrium and kinetic modeling of adsorption of reactive dye on cross linked chitosan beads. J. Haz. Mate., 93, 233-248 (2002).

Chowdhary, S., R. Mishra, P. Saha and P. Kushwaha: Adsorption thermodynamics, kinetics and isostearic heat of adsorption of malachite green onto chemically modified rice husk. Desalination, 265, 159 (2011).

Dada, AO., A.P. Olalekan, A.M. Olatunya AM and O.Dada: Langmuir, Freundlich, Temkin and Dubinin - Radushkevich isotherms studies of equilibrium sorption of $\mathrm{Zn}$ (11) onto phosphoric acid modified rice husk. IOSR J. Appl. Chem., 3, 38-45(2012).

Dallel, R., A. Kesraoui and M. Seffen: Biosorption of cationic dye onto
Phragmites australis fibers: Characterization and mechanism. J. Environ. Chem. Eng., 6, 7247-7256 (2018).

Deniz, F. and R.A. Kepekci: Dye biosorption onto pistachio by-product: A green environmental engineering approach. J. Mol. Liq., 219,194$200(2016)$

Diaper, C., V.M. Correia and S.J. Judd: The use of membranes for the recycling of water and chemicals from dye house effluents: An economic assessment. J. Soc. Dyers. Colourists, 112, 273-281 (1996).

Farkas, V.A., A. Felinger, A. Hegedusova, I. Dekany and T. Pernyeszi: Comparative study of the kinetics and equilibrium of phenol biosorption on immobilized white-rot fungus Phanerochaete chrysosporium from aqueous solution. Colloids Surfaces $B$ Biointerfaces, 103,381-390 (2013).

Georgieva, V.G., M.P. Tavlieva, S.D. Genieva and T. Vlaev: Adsorption kinetics of $\mathrm{Cr}(\mathrm{VI})$ ions from aqueous solutions onto black rice husk ash. J. Mol. Liq., 208, 219-226 (2015).

Hameed, B.H.: Evaluation of papaya seeds as a novel non-conventional low-cost adsorbent for removal of methylene blue. J. Hazar. Mater., 162, 939-944 (2009).

lqbal, M. and A. Saeed: Biosorption of reactive dye by loofa spongeimmobilized fungal biomass of Phanerochaete chrysosporium. Proc. Biochem., 42, 1160-1164 (2007).

Kamranifar, M., M. Khodadadi and V. Samiei: Comparison the removal of reactive red 195 dye using powder and ash of barberry stem as a low cost adsorbent from aqueous solutions: Isotherm and kinetic study. J. Mol. Liq., 255, 572-577 (2018).

Khalaf, M.A.: Biosorption of reactive dye from textile waste water by nonviable biomass of Aspergillus niger and Spirogyra sp. Bioresour. Technol., 99, 6631-6634 (2008).

Khan, A., S. Afzal, H. Mustafa and M. Qumreen: Data article for adsorption of chemically activated fuller $\backslash$ s earth and rice husk for removal of dri-marine reactive red dye. Data Br., 21, 189-200 (2018).

Lin, S.H. and F.C. Peng: Treatment of textile waste water by electrochemical methods. Wat. Res., 2, 277-282 (1994).

Marzinkowski, J.M., B. Van Clewe and G. Van Clewe: Water cycle management by membrane filtration of colored wastewater. Melliand Textile Reports, 79, 174-177 (1998).

Mcmullan, G., C. Meehan, A. Conneely, N. Kirby, T. Robinson, P. Nigam, I.M. Banat, R. Marchant and W.F. Smyth: Microbial decolourisation and degradation of textile dyes. Appl. Microbiol. Biotechnol., 56, 81-87 (2001).

Morosanu, I., C.Teodosiu, A. Coroaba and C. Paduraru: Sequencing batch biosorption of micropollutants from aqueous effluents by rapeseed waste: Experimental assessment and statistical modelling. J. Environ. Manage., 230, 110-118 (2018).

Nayak, A.K. and A. Pal: Green and efficient biosorptive removal of methylene blue by Abelmoschus esculentus seed: Process optimization and multi-variate modeling. J. Environ. Manage., 200,145-159 (2017)

Ncibi, M.C., A.M.B. Hamissa and A. Fathallah: Biosorptive uptake of methylene blue using Mediterranean green alga Enteromorpha spp. J. Hazard Mater., 170,1050-1055 (2009).

Nirmal Kumar, J.I. and C. Oommen: Removal of heavy metals by biosorption using freshwater alga Spirogyra hyalina. J. Environ. Biol., 33, 27-31 (2012)

Pavan, F.A., E.S. Camacho, E.C. Lima, G.L. Dotto, V.T.A. Branco and S.L.P. Dias: Formosa papaya seed powder (FPSP): Preparation, 
characterization and application as an alternative adsorbent for the removal of crystal violet from aqueous phase. J. Environ. Chem. Eng., 2, 230-238 (2014).

Rangabhashiyam, S., S. Lata and P. Balasubramanian: Biosorption characteristics of methylene blue and malachite green from simulated wastewater onto Carica papaya wood biosorbent. Surf. Interf., 10, 197-215 (2018).

Saeed, A., M. Iqbal and S.I. Zafar: Immobilization of Trichoderma viride for enhanced methylene blue biosorption: Batch and column studies. J. Haz. Mater., 168, 406-415 (2009).

Shakoor, S. and A. Nasar: Adsorptive treatment of hazardous methylene blue dye from artificially contaminated water using Cucumis sativus peel waste as a low-cost adsorbent. Ground Sustain Dev., 5,152-159 (2017).

Singh, H., G. Chauhan, A.K. Jain and S.K. Sharma: Adsorptive potential of agricultural wastes for removal of dyes from aqueous solutions. J. Environ. Chem. Eng., 5, 122-135 (2017)

Singh, S., A. Tripathi and S.K. Srivastav: Comparative biosorption competencies of Ficus syzygium and Mangifera seeds for hexavalent chromium mitigation from polluted water. J. Environ.
Biol., 39, 159-165 (2018)

Thippeswamy, B., C.K. Shivakumar and M. Krishnappa: Bioaccumulation potency of Aspergillus niger and Aspergillus flavus for removal of heavy metals. J. Environ. Biol., 33 1063-1068 (2012)

Tokuda, J., R. Ohura and T. Iwasaki: Decolouration of azo dyes by hydrogen catalyzed by water soluble manganese porphyrins. Textile Res. J., 69, 956-960 (1999).

Unuabonah, El., G.U. Adie, L.O. Onah and O.G. Adeyemi: Multistage optimization of the adsorption of methylene blue dye onto defatted Carica papaya seeds. Chem. Eng. J.,155, 567-579 (2009).

Wanyonyi, WC., J.M. Onyari and P.M. Shiundu: Adsorption of congo red dye from aqueous solutions using roots of Eichhornia crassipes: Kinetic and equilibrium studies. Energy. Procedia., 50, 862-869 (2014).

Yoshida, Y., S. Ogata and S. Nakamatsu: Decolourization of azo dye using atomic hydrogen permeating through a Pt- modified $\mathrm{Pd}$ sheet electrode. Electrochem. Acta., 45, 409-419 (2001).

Zaharia, C. and D. Suteu: Option and solution for textile effluent decolourization using some specific physicochemical treatment steps. Environ. Engg. Manage. J., 11, 493-509 (2012) 